九州大学学術情報リポジトリ

Kyushu University Institutional Repository

\title{
Embryogenesis in the Cattle Tick, Haemaphysalis longicornis
}

Shiraishi, Satoshi

Zoological Laboratory, Faculty of Agriculture, Kyushu University

Yano, Yasuhiro

Zoological Laboratory, Faculty of Agriculture, Kyushu University

Uchida, Teruaki

Zoological Laboratory, Faculty of Agriculture, Kyushu University

https://doi.org/10.5109/23902

出版情報：九州大学大学院農学研究院紀要. 34 (3)，pp. 265-272，1990-02. Kyushu University バージョン：

権利関係 : 


\title{
E mbryogenesis in the Cattle Tick, Haemaphysalis longicornis
}

\author{
Satoshi Shiraishi, Yasuhiro Yano* and Teru Aki Uchida \\ Zoological Laboratory, Faculty of Agriculture, \\ Kyushu University 46-06, Fukuoka 812, Japan \\ (Received August 29, 1989)
}

\begin{abstract}
The aim of this paper is to describe the outline of embryonic development of the cattle tick, Haemuphysalis longicornis, with phase contrast and light microscopes. Since intralecithal nuclei were migrating towards the egg periplasm even immediately after oviposition, the process of intralecithal nuclear divisions was not recognizd, suggesting that the divisions have already finished when the egg is passing through the oviduct. The monocellular blastoderm was formed in the egg periplasm by the 3rd day. The future ventral side of a larva was characterized by the first appearance of the germ band in the blastoderm on the 4th day, and the polarity of the gnathosoma and idiosoma of the larva was determined by blastokinesis by the 7th day. In the tick, the 4th leg anlage appeared on the 7th day after oviposition. Accumulation of guanine in the rectal sac on the 8th day suggested completion of the digestive system and digestion of the yolk. The embryo developed into a pharate larva on the 12th day. Regression and retraction of the 4th leg anlage occurred by the time of full formation of the cuticle on the 14th day. The egg hatched out into a larva on the 17th day.
\end{abstract}

\section{INTRODUCTION}

The cattle tick, Haemaphysalis longicornis, is widely distributed in Australia, New Zealand, New Caledonia, Fiji, Japan, Korea, northeastern parts of China and USSR, and is a vector of the viruse causing Russian spring-summer encephalitis, the rickettsia, Coxiella burneti (Q fever), and the protozoon, Theileria sergenti (Hoogstraal et al., 1968).

The species, which is the most dominant tick in Japanese pastures, causes theileriosis among cattle, and consequently retarded development and lowered fecundity (Ishihara, 1968). Accordingly, remedial procedures against the disease and tick-control are urgent needs for the progress of animal husbandry. In order to perform efficient tick-control, it is indispensable not only to establish new methods for tick-control (e. g. development of repellents and acaricides), but also to accumulate fundamental knowledge on the tick ecology, physiology and epidemiology.

A few microscopic studies on tick embryogenesis have been fragmentarily made in Ornithodoros moubata (Aeschlimann, 1958) and Hyalommadromedarii (Anderson, 1973 ; El Gohary et al.,1986), and scanning electron microscopic observations have been done only in 0. moubata (Aeschlimann and Hess, 1984).

The present study is therefore carried out to determine the outline of embryonic development of the cattle tick with phase contrast and light microscopes. Further,

*Present Address: Department of Immunology and Parasitology, Fukui Medical School, Matsuoka, Fukui 910-11, Japan. 
there are given brief discussions about the relationship between intralecithal nuclear divisions and fertilization, and about the process of regression and retraction of the 4th leg anlage.

\section{MATERIALS AND METHODS}

In order to examine the embryonic development, eggs (ca. $0.5 \times 0.4 \mathrm{~mm}$ ) were daily collected from the oviposition day to the hatching day at $30^{\circ} \mathrm{C}$ and $100 \% \mathrm{RH}$. For phase contrast microscopy, the eggs (about 20 eggs per day) were fixed in Carnoy's fluid, dehydrated in alcohol, and whole-mount preparations were made. For light microscopy, the eggs were fixed in the same fixative, whose egg-shells were softened with $3 \% \mathrm{NaClO}$, dehydrated in alcohol, embedded and sectioned with Kulzer Histoset ; sections (ca. $3 \mu \mathrm{m}$ ) were stained with toluidine blue.

\section{RESULTS}

\section{Phase contrast microscopical observations}

On the oviposition day, only yolk granules were faintly visible from the surface of eggs (Fig. 1). On the 2nd day after oviposition, cleavage nuclei were distributed uniformly on the egg surface (Fig. 2). On the 4th day, the blastoderm cells proliferated to form the germ band becoming the future ventral side of the larval idiosoma, and then metamerization occurred in the germ band ; anlagen of the 1st to 3rd legs differentiated from both the ends of the metameres concerned (Fig. 3). On the 5th day, the germ band was separated into two bilateral parts by the ventral sulcus (neural groove); the leg buds originated from the anlagen became long towards the ventral sulcus (Fig. 4). On the 7th day, the germ band was longitudinally contracted by blastokinesis ; the three pairs of legs elongated towards the center of the ventral surface, and the 4th leg anlage was recognized; the Malpighian tubules began to differentiate (Fig. 5). On the 8th day, the 1st to 3rd legs lengthened more, the rectal sac accumulated guanine in the lumen, and the salivary gland shaped like a cluster differentiated (Fig. 6). On the 12th day, the embryo developed into a pharate larva, and the 1st to 3rd legs commenced segmentation and formed their claws, but the 4th leg anlage remained undeveloped ; a guanine mass in the rectal sac increased in size (Fig. 7). On the 14th day, the 4th leg anlage could be no longer recognized and the cuticle was fully formed (Fig. 8), and the egg hatched out into a larva with the three pairs of legs within additional 2 or 3 days later (Fig. 9).

\section{Light microscopical observations}

In the egg just after oviposition, intralecithal nuclei were migrating towards the egg periplasm, but had not yet reached the egg surface (Fig. 10). On the 1st day, cleavage nuclei began to appear on the egg surface (Fig. 11). The monocellular blastoderm was formed in the egg periplasm by superficial cleavage until the $3 \mathrm{rd}$ day, and some intralecithal nuclei remained in the cytoplasm between yolk granules as vitellophages even after the majority of them had migrated to the periplasm (Fig. 12). On the 5th day, the metamerized germ band forming the ventral side of the future larval idiosoma occupied more than half of the egg proper (Fig. 13), and contracted 

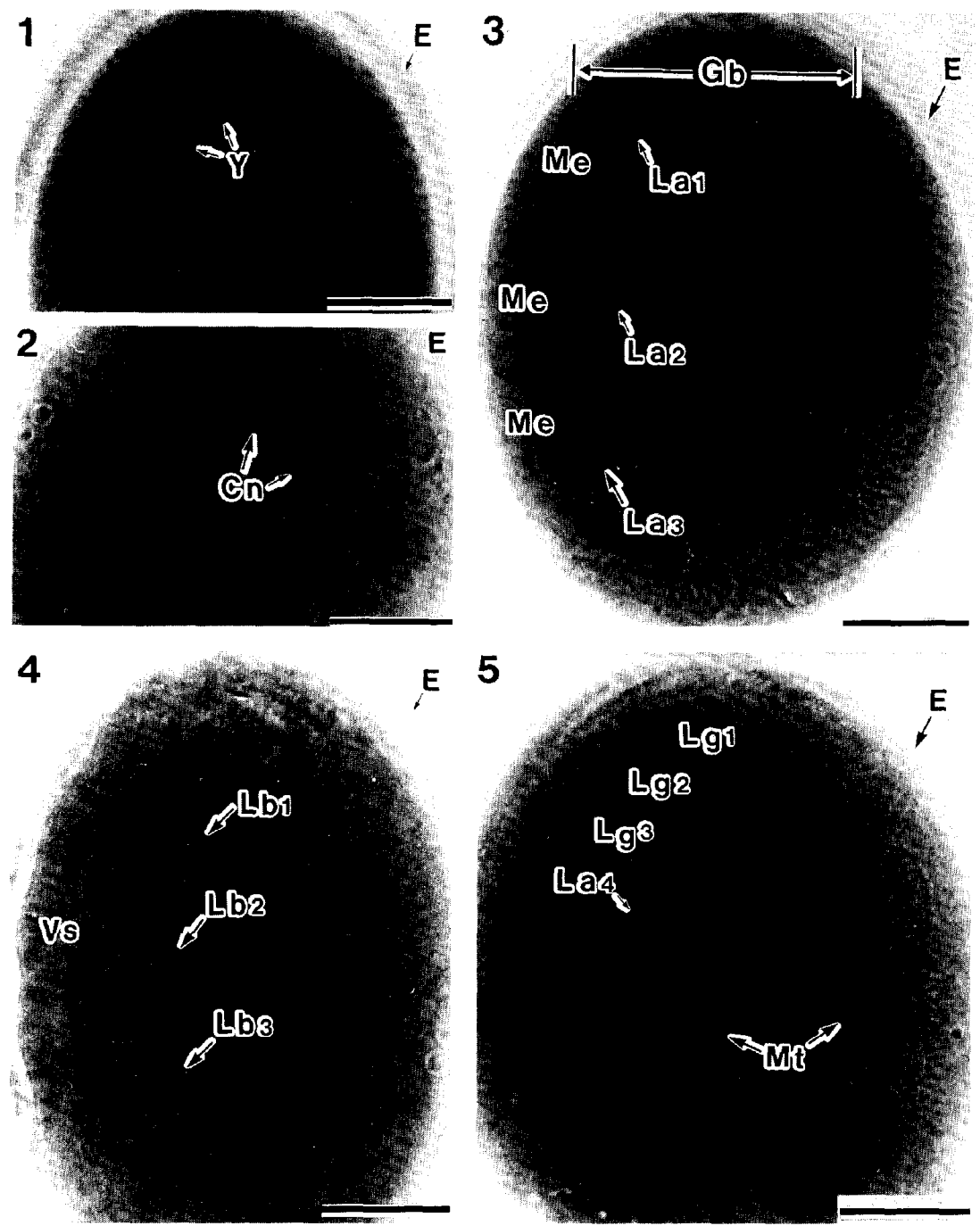

Figs. 1-9. Phase contrast micrographs of embryogenesis in Haemaphysalis longicornis $\left(30^{\circ} \mathrm{C}, \mathbf{1 0 0 \%} \mathrm{RH}\right)$. Scale bar $0.1 \mathrm{~mm}$.

Fig. 1. An egg just after oviposition showing faintly visible yolk granules (Y). E, egg-shell.

Fig. 2. An egg on the 2 nd day after oviposition showing cleavage nuclei $(\mathrm{Cn})$ which reached the egg surface. E, egg-shell.

Fig. 3. An egg on the 4th day showing differentiation of the metamerized germ band (Gb) and anlagen of the legs (La). E, egg-shell ; La 1, 1st leg anlage ; La 2, 2nd leg anlage ; La 3, 3rd leg anlage ; Me, metamere.

Fig. 4. An egg on the 5th day showing elongation of the leg buds (Lb) towards the ventral sulcus (Vs). E, egg-shell ; Lb 1, 1st leg bud ; Lb 2, 2nd leg bud ; Lb 3, 3rd leg bud.

Fig. 5. An egg on the 7th day showing differentiation of the Malpighian tubule (Mt) and the 4th leg anlage (La 4). E, egg-shell ; Lg 1, 1st leg ; Lg 2, 2nd leg ; Lg 3, 3rd leg. 


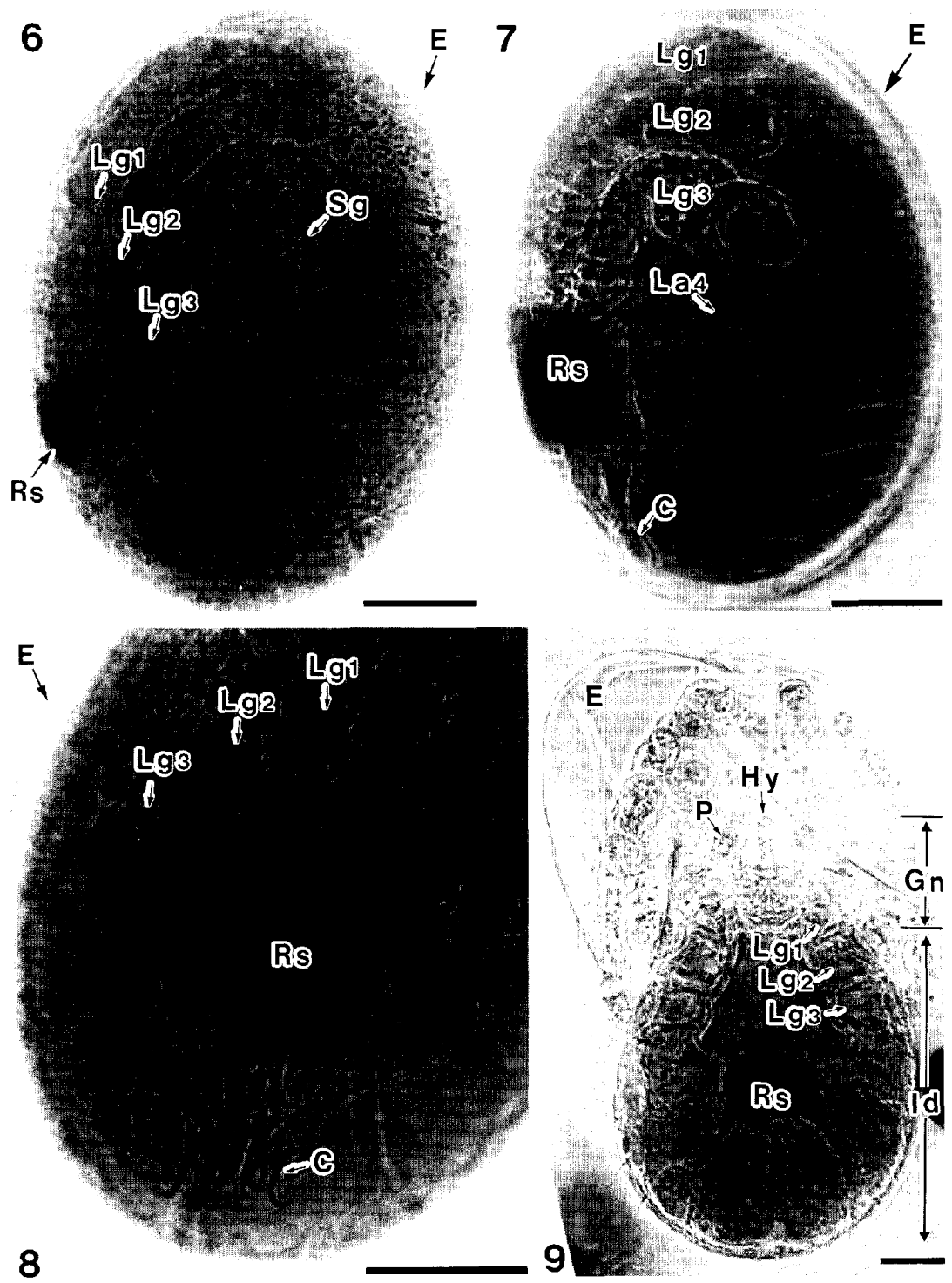

Fig. 6. An egg on the 8th day showing accumulation of guanine in the rectal sac (Rs) and differentiation of the salivary gland (Sg). E, egg-shell ; Lg 1,lst leg ; Lg 2, 2nd leg ; Lg 3, 3rd leg.

Fig. 7. A pharate larva on the 12th day showing segmentation of the legs. C, claw ; E, egg-shell ; La 4, 4th leg anlage ; Lg 1, 1st leg ; Lg 2, 2nd leg ; Lg 3, 3rd leg ; Rs, rectal sac.

Fig. 8. A pharate larva on the 14th day showing disappearance of the 4th leg anlage. C, claw; Lg 1, 1st leg; Lg 2, 2nd leg; Lg 3, 3rd leg; Rs, rectal sac.

Fig. 9. A larva hatched out on the 17th day. E, egg-shell; Gn, gnathosoma ; Hy, hypostome; Id, idiosoma ; Lg 1, 1st leg; Lg 2, 2nd leg; Lg 3, 3rd leg; P, palp; Rs, rectal sac. 

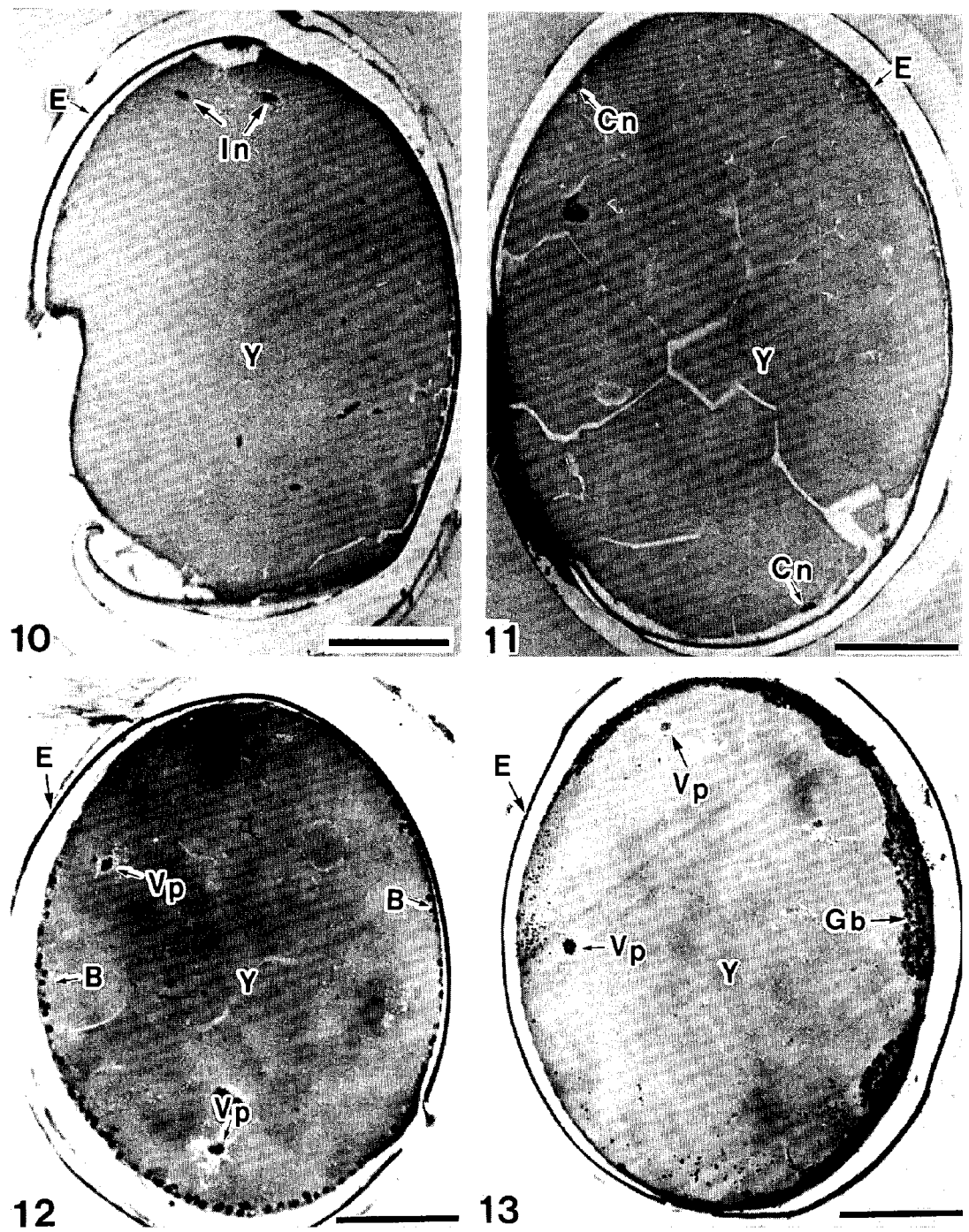

13

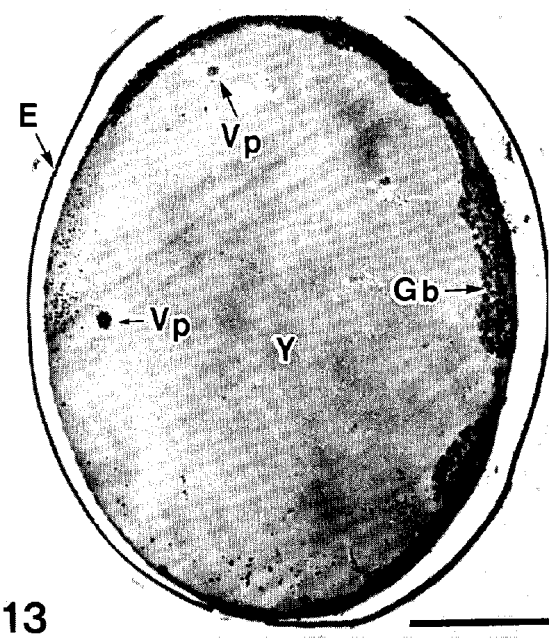

Fig. 10-17. Light microghaphs of embryogensis in Haemaphysalis longicornis $\left(30^{\circ} \mathrm{C}\right.$, $100 \%$ RH). Scale bar O.lmm.

Fig. 10. Longitudinal section of an egg just after oviposition showing intralecithal nuclei (In) which are migrating towards the egg periplasm. E, egg-shell ; Y, yolk granule.

Fig. 11. Longitudinal section of an egg on the 1st day after oviposition showing cleavage nuclei $(\mathrm{Cn})$ which reached to the egg surface. E, egg-shell ; Y, yolk granule. Fig. 12. Longitudinal section of an egg on the 3rd day showing the blastoderm (B) in the egg periplasm and vitellophages $(\mathrm{Vp})$ in the cytoplasm between yolk granules $(\mathrm{Y})$. E, egg-shell.

Fig. 13. Parasagittal section of an egg on the 5th day showing the metamerized germ band (Gb). E, egg-shell ; Vp, vitellophage ; Y, yolk granule. 

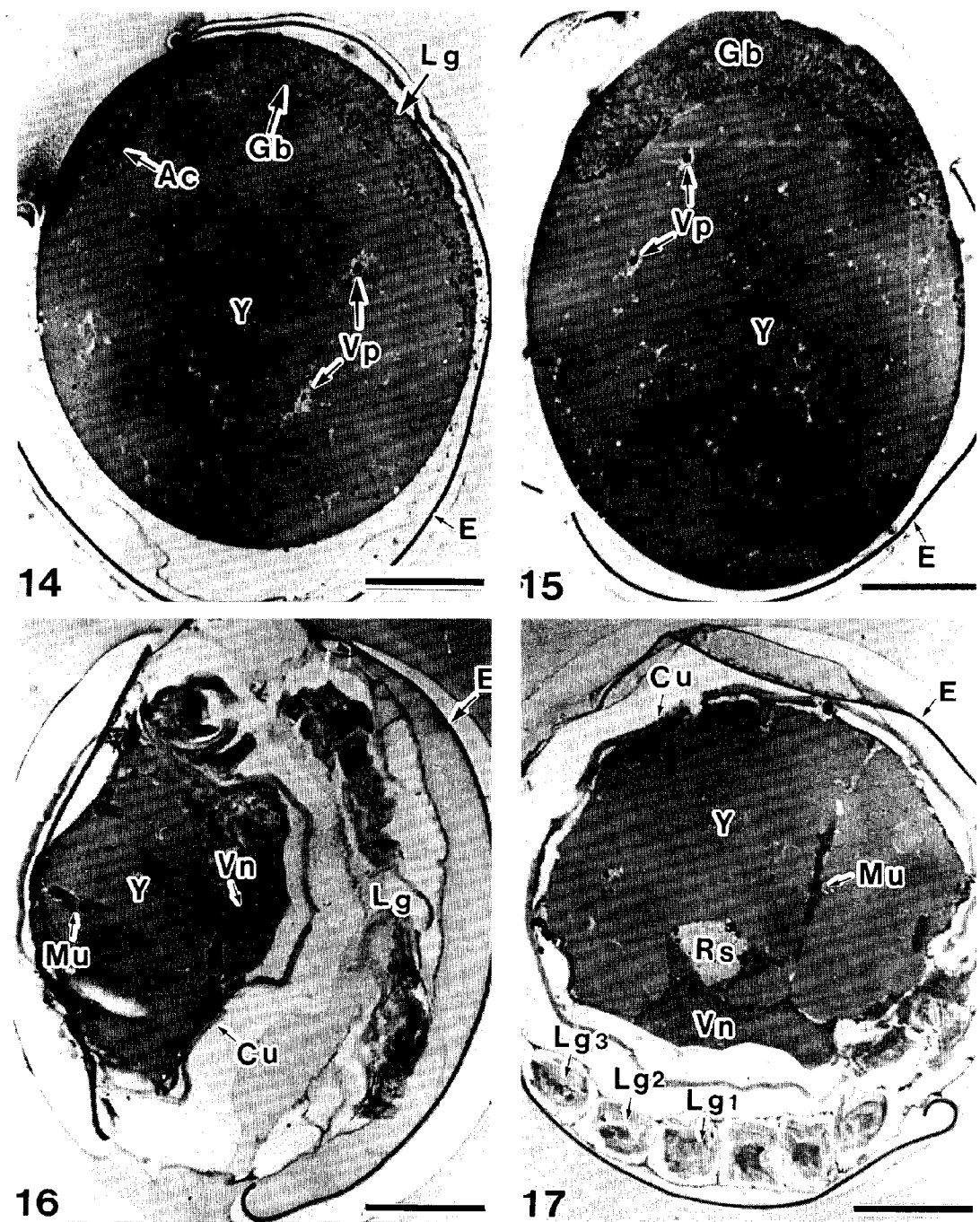

Fig. 14. Parasagittal section of an egg on the 7th day showing the contracted germ band (Gb) by blastokinesis and an elongated leg (Lg). Ac, acron; E, egg-shell ; Vp, vitellophage ; Y, yolk granule.

Fig. 15. Obliquely horizontal section of an egg on the same day as in Fig. 14. E, egg-shell ; Gb, germ band ; Vp, vitellophage ; Y, yolk granule.

Fig. 16. Parasagittal section of a pharate larva on the 16th day showing the complete cuticle $(\mathrm{Cu})$, muscle $(\mathrm{Mu})$ and ventral nerve cord (Vn). E, egg-shell ; Lg, leg ; Y, yolk granule.

Fig. 17. Obliquely cross section of a pharate larva on the same day as in Fig. $16 . \mathrm{Cu}$, cuticle ; E, egg-shell ; Lg 1, 1st leg; Lg 2, 2nd leg; Lg 3, 3rd leg ; Mu, muscle ; Rs, rectal sac; Vn, ventral nerve cord ; Y, yolk granule. 
towards the acron (a part of the gnathosoma in future) by blastokinesis on the 7th day (Figs. 14 and 15). Although the embryos on the 8th-15th day were not observed because of preparation failures, the pharate larva on the 16th day had completed deposition of the cuticle and differentiated the ventral nerve cord, muscle and rectal sac ; a yolk mass was still maintained in the pharate larva (Figs. 16 and 17). The process of the above embryogenesis was summarized in Table 1.

Table 1. Embryogenesis at $30^{\circ} \mathrm{C}$ and $100 \%$ RH in Haemaphysalis Zongicornis.

\begin{tabular}{|c|c|}
\hline $\begin{array}{l}\text { Days after } \\
\text { oviposition }\end{array}$ & Embryonic development \\
\hline 0 & Migration of intralecithal nuclei towards the egg periplasm \\
\hline 1 & Appearance of cleavage unclei on the egg surface \\
\hline 2 & Formation of the blastoderm \\
\hline 4 & $\begin{array}{l}\text { Formation of the germ band and its metamerization, differ- } \\
\text { entiation of the } 1 \text { st to } 3 \text { rd leg anlagen }\end{array}$ \\
\hline 5 & Elongation of the 1 st to 3 rd leg buds \\
\hline 7 & $\begin{array}{l}\text { Blastokinesis of the germ band, differentiation of the 4th } \\
\text { leg anlage and the Malpighian tubules }\end{array}$ \\
\hline 8 & $\begin{array}{l}\text { Accumulation of guanine in the rectal sac and differenti- } \\
\text { ation of salivary glands }\end{array}$ \\
\hline 12 & $\begin{array}{l}\text { Development into a pharate larva, segmentation of the legs } \\
\text { and formation of claws }\end{array}$ \\
\hline 14 & $\begin{array}{l}\text { Disappearance of the } 4 \text { th leg anlage and completion of the } \\
\text { cuticle }\end{array}$ \\
\hline 17 & Hatching out into a larva \\
\hline
\end{tabular}

\section{DISCUSSION}

This is the first report on embryogenesis in $H$. Zongicornis. Tick eggs belong to the centrolecithal type with a central nucleus. Even in the egg immediately after oviposition, intralecithal nuclei were migrating towards the egg periplasm surrounding a mass of yolk granules : accordingly, the process of intralecithal nuclear divisions was not seen in this study. The reason for this is that fertilization probably occurs in the ovarian lumen at the ovulation time (Yano et al., 1989), and consequently that intralecithal nuclear divisions seem to have already finished when the egg is passing through the ovarian lumen and/or the oviduct.

The monocellular blastoderm was formed in the egg periplasm by superficial cleavage. The portion, from which the ventral side of a larva in future is produced, was characterized by the first appearance of the germ band in the blastoderm, and the gnathosoma and idiosoma in the future larva was determined by blastokinesis. Similar phenomena have been reported in H. dromedarii (Anderson, 1973) and 0. moubata (Aeschlimann and Hess, 1984).

As another unique feature, regression and retraction of the 4th leg anlage occurred in the course of embryogenesis. Although it has been presented that differentiation of the 4th leg anlage coincides with that of the 1st to 3rd leg anlagen in O.moubata (Aeschlimann and Hess, 1984), in H. Zongicornis the 4th leg anlage appeared for the first time on the 7th day after oviposition, when the 1st to 3rd legs elongated ; regression and retraction of the 4th leg anlage seemed to occur at the time of full formation of 
the cuticle in the pharate larva on the 14th day. Accumulation of guanine in the rectal sac on the 8th day suggested completion of the digestive system and digestion of the yolk.

\section{ACKNOWLEDGEMENTS}

We wish to express our hearty appreciation to Dr. T. Mōri and Mrs. A. Murakami, née Fukube, the then undergraduate student for their help in making preparations, and graduate students of our laboratory for their help in collection ticks. Thanks are also due to Professor E. W. Jameson, Jr., University of California for comments on the manuscript. This work was supported in part by a Grant-in-Aid from the Ministry of Education, Science and Culture, Japan.

\section{REFERENCES}

Aeschlimann, A. 1958 Développement embryonnaire d' Ornithodorus moubatu (Murray) et transmission transovarienne de Borelia duttoni. Acta Trop., $15: 15-64$

Aeschlimann, A. and E. Hess 1984 What is our current knowledge of acarine embryology? In "Acarology VI", Vol. 1, ed. by D. A. Griffiths and C. E. Bowman, Ellis Horwood Limited, Chichester, pp. 90-99

Anderson, D. T. 1973 Embryology and Phylogeny in Annelids and Arthropods. International Series of Monographs in Pure and Applied Biology. Division : Zoology, Vol. 50, Pergamon Press, Oxford

El Gohary, M., M. Y. Kamel and M. H. Madbouly 1986 On the morphology of developing eggs of the camel tick Hyalommadromedarii Koch, 1844. Can. J.Zool., 64: 1994-1997

Hoogstraal, H., F. H. S. Roberts, G. M. Kohls and V. J. Tipton 1968 Review of Haemaphysalis (Kaiseriana) longicornis Neumann (resurrected) of Australia, New Zealand, New Caledonia, Fiji, Japan, Korea, and northeastern China and USSR, and its parthenogenetic and bisexual populations (Ixodoidea, Ixodidae). J.Parasit., 54 : 1197-1213

Ishihara, T. 1968 Bovine piroplasmosis in Japan. Jpn. Agric. Res. Q., $3:$ 23-31

Yano, Y., T. Mōri, S. Shiraishi and T. A. Uchida 1989 Ultrastructure of oogenesis in the adult cattle tick, Haemaphysalis longicornis. J. Fac. Agr., Kyushu Univ., 34: 53-67 